A- hHtt

B- polyQ-hHtt; LacZ

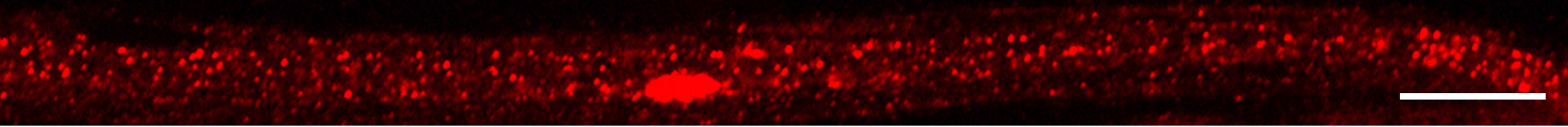

C- polyQ-hHtt; P42

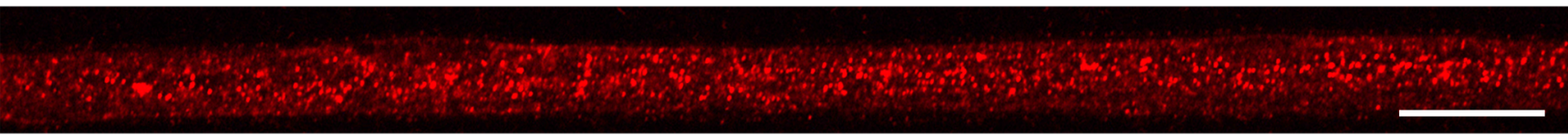

\title{
D- Quantification
}

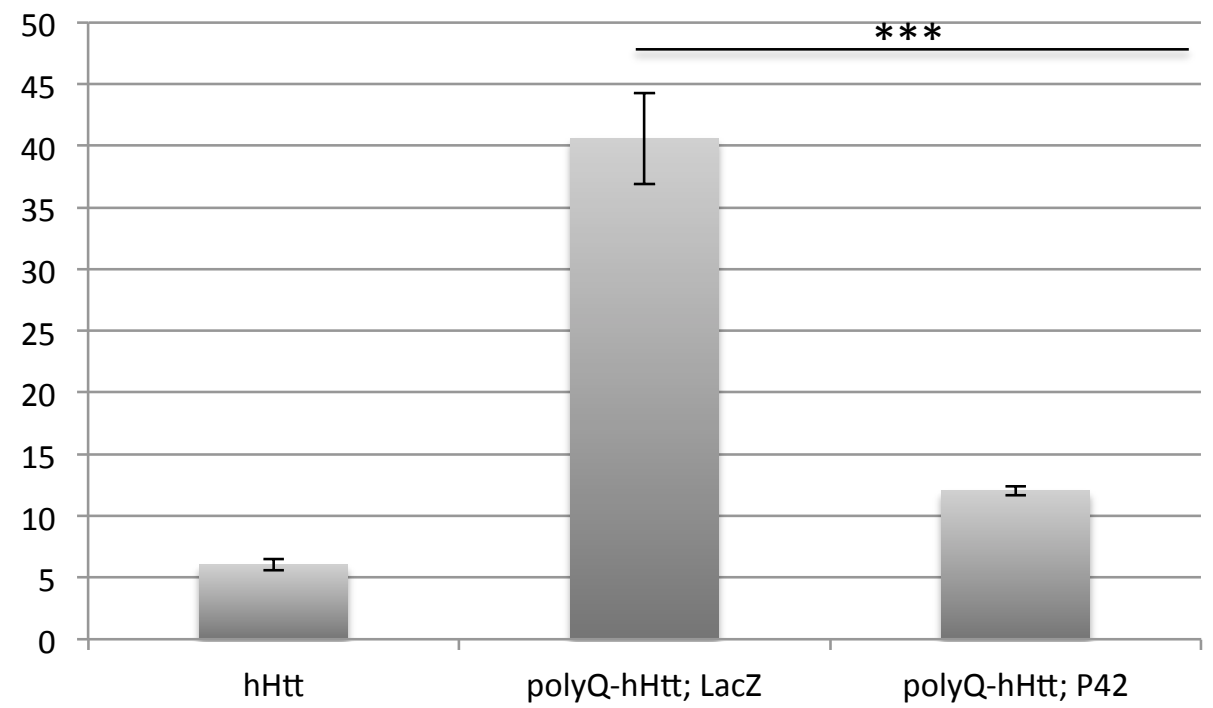

Figure S7: Confocal images of third larval peripheral nerves expressing $\mathrm{hH} \mathrm{tt}^{548 a a}$, detected by anti-hHtt (Hu-4C8) (in red) expressing in A- OK6-Gal4; UAS-0Q-hHtt ${ }^{548 a a}$ (hHtt). B- OK6Gal4; UAS-128Q-hHtt548aa; UAS-LacZ. C- OK6-Gal4; UAS-128Q-hHtt548aa; UAS-P42. DQuantification of particle density for $100 \mu \mathrm{m}$ axon segments $(n=10)$, using ImageJ particle quantification Plugin. Data were analysed by using the Student's $t$-test: ${ }^{* * *} p<0.001$. 